\title{
Spatial Reasoning Based on the Tendency of Gestalt Law to Solve Geometry Problems
}

\author{
Dewi Risalah $^{1,2, *}$, Toto Nusantara ${ }^{2}$, Akbar Sutawidjaja $^{2}$, Susiswo $^{2}$ \\ ${ }^{1}$ Department of Mathematics Education, Institut Keguruan dan Ilmu Pendidikan PGRI Pontianak (IKIP-PGRI Pontianak), Indonesia \\ ${ }^{2}$ Department of Mathematics Education, State University of Malang, Indonesia
}

Received October 7, 2019; Revised October 30, 2019; Accepted November 8, 2019

Copyright $\bigcirc 2019$ by authors, all rights reserved. Authors agree that this article remains permanently open access under the terms of the Creative Commons Attribution License 4.0 International License

\begin{abstract}
Spatial reasoning is the processing of non-verbal information in the form of images or symbols to solve problems. In this regard, this research aims to describe students' spatial reasoning based on Gestalt law trend to solve geometry problems. The approach of this research is qualitative research. Qualitative research is used to describe students' reasoning based on Gestalt law tendency to solve geometry problems. The subjects in this research were students who had studied geometry lessons. This research describes one categories of students' spatial reasoning based on Gestalt law, namely students' reasoning with the closeness law tendency.
\end{abstract}

Keywords Spatial Reasoning, Gestalt Law, Geometry Problems

\section{Introduction}

Spatial reasoning is the processing of non-verbal information in the form of images or symbols [9] to solve problems. According to [5] it is stated that spatial thinking or reasoning, physically and mentally involves ourselves, the location and movement of objects. Spatial reasoning is very important in informing cognitive abilities to investigate and solve problems, especially problems in mathematics.

In solving a problem, someone will do a mental process by using all the perceptual knowledge that is owned and determine the right strategy to solve the problem. There is an organizational theory of perception about understanding in solving problems, namely the Gestalt Theory. [8] stated that in making a model of perceptual models, people need a continuity of good spatial reasoning from Gestalt Theory. Previous writers have argued that Gestalt principles provide a useful guiding framework for categorizing multi-sensory displays [1] Gestalt is one of the schools of psychology that studies a phenomenon as a whole or totality, wherein it contains four laws namely proximity law, closeness law, equality law, and continuity law. These four laws will support spatial reasoning.

Spatial reasoning is very important in informing our ability to investigate and solve problems, especially problems in mathematics. [4], states that spatial reasoning is not only important in mathematics but also in all fields of study. In the Ontario curriculum, it combines spatial and geometry sense into one unit because both are related to each other. In line with the curriculum, [6] states the importance of spatial reasoning skills in STEAM, geometry, measurement and problem solving both inside and outside of school.

Geometry is one of the materials in mathematics that has been taught to students in junior high schools. Geometry is the study of shapes and images. Without spatial ability, students cannot fully appreciate nature [2]. In geometry, students are required to be able to imagine, manipulate, and compare objects in solving problems. For example, if students are asked to find the broad shaded comparisons of a geometry, then what students can do is imagine and manipulate the shape of the geometry is one way to solve it.

In the process of solving a problem, someone will do a mental process by using all the knowledge that is owned and determine the right strategy to solve the problem. [7] reveals two kinds of problems, namely (a) problems to find, can be theoretical or practical, abstract or concrete including riddle, and (b) problems to prove, to show that a statement is true or false (not both). In mathematics, problems are usually in the form of mathematical problems, but not all math problems are problems. [3] explained that a question is called a problem depending on the knowledge someone has therefore, a question is a problem for someone but it might not be a problem for others.

Based on the above background, the formulation of the problem in this research is "How is the spatial reasoning of 
students based on Gestalt law tendency in solving geometry problems?". By knowing this spatial reasoning, it is expected to be able to give ideas for teacher in improving geometry lesson by paying attention to students' spatial reasoning so it will be more directed.

\section{Research Method}

The approach in research is qualitative used to describe student reasoning based on the Gestalt law in solving geometry problems. The subjects in this research were students who had studied geometry lessons. Subjects were taken from several of these students based on students' spatial reasoning abilities. This research was conducted to the eight graders students of Junior High School of 21 East Pontianak which is located at Jalan Tanjung Raya 2 East Pontianak.

The researcher initially gave the subject geometry problem solving task to the subject to find out the spatial reasoning of students. From the results of the answers given by this subject, the researcher will see whether there are students who use spatial reasoning, namely imagining, manipulating, or comparing objects. All the components of spatial reasoning will be associated using Gestalt law. This can be seen in thinking framework diagram (see Figure 1).
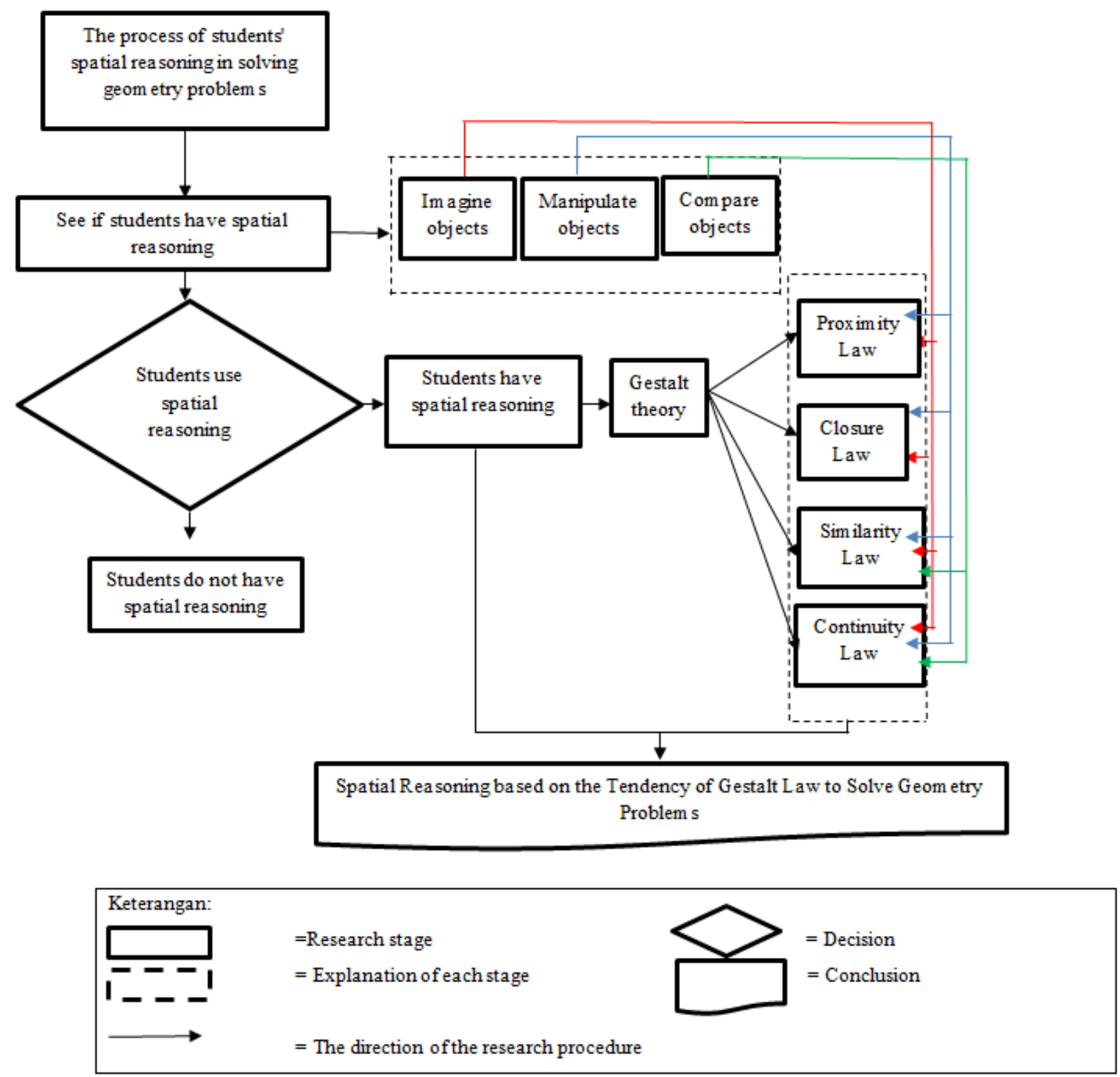

Figure 1. Thinking Framework Diagram 


\subsection{The Results and Process of Analysis on Subject Data in Solving Problem}

Student who is the subject of the question is D7. At the completion problem, the subject $\mathrm{D} 7$ answers by imagining and manipulating, the existing object so as to form a unity of form equality, which can then be compared as a solution in solving the problem of wide area. Students show (with the index finger left and right) the position of the PQRS square after being rotated which will form an image like this:

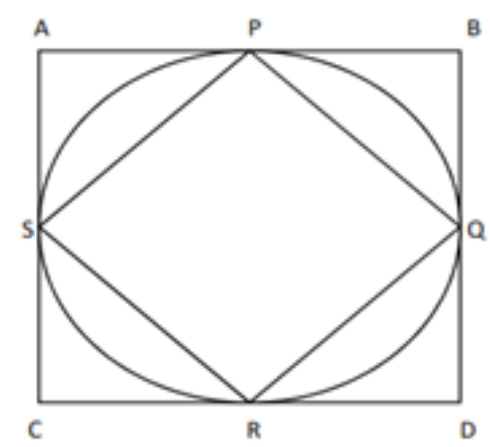

Figure 2. Problem

From the picture above, it can be seen that there is an SAP triangle where it is known that the length of the side $\mathrm{AS}=\mathrm{AP}$ is $1 / 2 \mathrm{p}$ units. The process of analyzing subject D7 data in solving the third problem is shown on Figure 3.

The process of solving t problem is known from D7 statement at the time of answering the researcher's question as follows:

$Q:$ What do you do in understanding the problem?

D7: To understand it, I first imagine and then see that the PQRS square is congruent with the $A B C D$ square. Then the square position of my $P Q R S$ rotates $\quad \square 90 \nabla \wedge O$ clockwise (it can also be counterclockwise) and from that rotation there is a QCP triangle where it is known the length of the $Q C$ side $=C P$ is $1 / 2 p$ units.

$Q:$ How do you solve it?

D7: When the length of each side of $Q C$ and $C P$ is known, the length of the side of $P Q$ can be determined by pythagoras formula, namely:

$$
\begin{aligned}
& P Q^{2}=Q C^{2}+C P^{2} \\
& P Q=\sqrt{ }\left(\left(\begin{array}{ll}
1 / 2 & \measuredangle p
\end{array}\right) \nabla \wedge 2+\left(\begin{array}{ll}
1 / 2 & (p) \nabla \wedge 2
\end{array}\right)\right. \\
& P Q=\sqrt{ }\left(1 / 4 p^{\wedge} 2+1 / 4 p^{\wedge} 2\right) \\
& P Q=\sqrt{ }\left(2 / 4 p^{\wedge} 2\right) \\
& P Q=1 / 2 p \quad \sqrt{ } 2 \text { unit }
\end{aligned}
$$

Since the length of PQ is known, the square area of PQRS is $(1 / 2 \mathrm{p} \quad \sqrt{ } 2)^{2}$ units of square area.

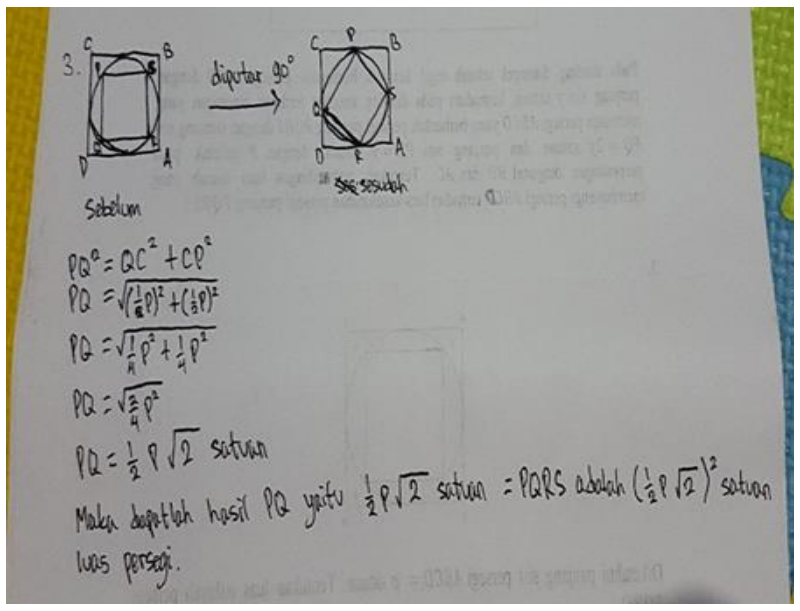

Figure 3. The Completion of question by subject D7

Based on the results of interviews and the work of subject D7, researchers can describe the components of spatial reasoning and Gestalt laws, as outlined in Table 1. 
Table 1. Description of the components of spatial reasoning and Gestalt Laws subject D7

\begin{tabular}{|c|c|c|c|}
\hline No & Subject narrative & $\begin{array}{c}\text { Component of spatial reasoning and } \\
\text { its explanation }\end{array}$ & $\begin{array}{c}\text { Component on Gestalt Laws and its } \\
\text { explanation }\end{array}$ \\
\hline 1. & $\begin{array}{l}\text { To understand this, I first imagined and } \\
\text { then saw that the PQRS square was } \\
\text { congruent with the ABCD square. }\end{array}$ & $\begin{array}{l}\text { (Imagine) } \\
\text { The subject imagined that in the } \\
\text { picture there was a PQRS square that } \\
\text { was congruent with the ABCD } \\
\text { square. } \\
\text { (Manipulating) } \\
\text { The subject looks at and shows that } \\
\text { in the picture there is a PQRS square } \\
\text { that is congruent with the ABCD } \\
\text { square. }\end{array}$ & $\begin{array}{l}\text { (Closure) } \\
\text { There are PQRS squares and ABCD squares } \\
\text { that overlap. } \\
\text { (Similarity) } \\
\text { PQRS square is congruent with ABCD square } \\
\text { with the same shape. }\end{array}$ \\
\hline 2. & $\begin{array}{l}\text { Then I turn the PQRS square position } \\
90^{\circ} \text { clockwise (can also be } \\
\text { counterclockwise) and from the rotation } \\
\text { there is a } \mathrm{QCP} \text { triangle where the known } \\
\text { length of the QC }=\mathrm{CP} \text { is } 1 / 2 \mathrm{p} \text { unit. }\end{array}$ & $\begin{array}{l}\text { (Manipulating) } \\
\text { The subject rotates a square position } \\
\text { of } 90^{\circ} \text { clockwise (can also be } \\
\text { counterclockwise) which results in a } \\
\text { QCP triangle where the side length } \\
\text { of QC =CP is known. }\end{array}$ & $\begin{array}{l}\text { (Closure) } \\
\text { Rotate a square PQRS of } 90^{\circ} \text { clockwise (can } \\
\text { also be counterclockwise). Close each other. } \\
\text { (Proximity) } \\
\text { QCP triangle where the known side length QC } \\
\text { = CP. Where the two sides are close together. } \\
\text { (Similarity) } \\
\text { QCP triangle where the known side length QC } \\
\text { =CP. Where both sides are the same size. }\end{array}$ \\
\hline 3. & $\begin{array}{l}\text { When the length of each side of the } \mathrm{QC} \\
\text { and } \mathrm{CP} \text { is known then the length of the } \\
\mathrm{PQ} \text { side can be determined by the } \\
\text { Pythagorean formula namely, } \\
\mathrm{PQ} 2=\mathrm{QC} 2+\mathrm{CP} 2 \\
\mathrm{PQ}=\sqrt{ }((1 / 2 \llbracket \mathrm{P}) \rrbracket \wedge 2+(1 / 2) \llbracket \mathrm{P}) \rrbracket \wedge 2) \\
\mathrm{PQ}=\sqrt{ }\left(1 / 4 \mathrm{p}^{\wedge} 2+1 / 4 \mathrm{p}^{\wedge} 2\right) \\
\mathrm{PQ}=\sqrt{ }\left(2 / 4 \mathrm{p}^{\wedge} 2\right) \\
\mathrm{PQ}=1 / 2 \mathrm{p} \sqrt{2} \text { unit } \\
\text { Because the length of } \mathrm{PQ} \text { is known, the } \\
\text { square area of PQRS is }(1 / 2 \mathrm{p} \sqrt{2})^{2} \text { units } \\
\text { of square area. }\end{array}$ & $\begin{array}{l}\text { (Comparing) } \\
\text { The length of each side of the } \mathrm{QC} \\
\text { and } \mathrm{CP} \text { is known where } \mathrm{QC}=\mathrm{CP} \text {, } \\
\text { then the } \mathrm{PQ} \text { side can be determined. }\end{array}$ & $\begin{array}{l}\text { (Similarity) } \\
\text { Side length QC = CP. Where both sides are } \\
\text { the same size. } \\
\text { (Continuity) } \\
\text { From the information obtained by the subject } \\
\text { and the subject is able to solve the problem } \\
\text { from the information, then there is a } \\
\text { continuation of information here, that is, the } \\
\text { square area of PQRS is }(1 / 2 \mathrm{p} \sqrt{2})^{2} \text { units of } \\
\text { square area. }\end{array}$ \\
\hline
\end{tabular}

Based on the results of interviews, work and description of the components of spatial reasoning and Gestalt Laws produced by D7, the flow of spatial reasoning that occurs is imagining- manipulating comparing with the explanation as follows:

D7 subject imagines the entire image in the square shape of $\mathrm{ABCD}$. The subject then imagines that in the $\mathrm{ABCD}$ square there is a circle and there is a square of PQRS, where the two squares are congruent. The subject then imagines that there is a possibility that the PQRS square can be rotated $\square 90 \Omega^{\wedge} 0$ (imagined). Then the subject sees and shows that in the picture there is a square of PQRS that is congruent with square ABCD. After that, the subject rotates a square position of $\left[90 \nabla^{\wedge} 0\right.$ clockwise (it can be counterclockwise) which produces a QCP triangle where the length of the $\mathrm{QC}=\mathrm{CP}$ (manipulating) side is known. The length of each side of QC and $\mathrm{CP}$ is known where $\mathrm{QC}=\mathrm{CP}$, then the $\mathrm{PQ}$ side can be determined. When the length of each side of QC and CP is known, the side length of PQ can be determined by the pythagorean formula, namely: Since the length of PQ is known, the square area of PQRS is $(1 / 2 \mathrm{p} \sqrt{ } 2)^{2}$ units of square area (compare). From the description above, the spatial reasoning that occurs in the subject of D7 is imagining-manipulating-comparing, then based on Gestalt law, the subject of D7 has a closeness tendency in solving problems. Subject D7 perceives that there is a square ABCD that covers the inside, where there is a circle and square PQRS. Spatial reasoning based on the Gestalt law that occurs in the subject D7 is shown on Figure 4.

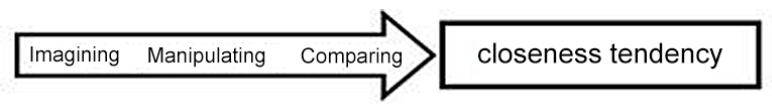

Figure 4. The flow of spatial reasoning on D7 subject with closeness tendency

\section{Conclusions}

Based on results described previously, when the subject solves the problem through the process of imagining, manipulating, then comparing, there is a tendency for the subject to use the closeness law when solving problems, because the subject tends to see the entire object that closes together as something intact. Can be explained that the subject reasoning process begins when the subject is able to change the orientation of the overall form in his mind (imagine), then the subject is able to do it by 
moving each part of the object so as to create a new form (manipulate). From the new form, the subject is then able to solve the problem given by comparing the shape of the form with the whole form (comparing). From this process, the subject tends to see the object as a whole that closes as a whole because there is no part that is ignored in solving the problem.

\section{Acknowledgements}

We are very grateful to experts for their appropriate and constructive suggestions to improve this template.

\section{REFERENCES}

[1] Chang, D. \& Nesbitt, K. (2005). Developing Gestalt-Based Design Guidelines for Multy-Sensory Display. The Proceeding Of NICTA- Hcsnet Multimodal User Interaction Workshop, The ACS Conference In Research And Practice In Information Technology CIRPIT, 57: 9-16.

[2] Guven, B; Kosa, T. (2008). The Effect of Dynamic Geometry Software on Student Mathematics Teachers Spatial Visualization Skill. The Turkish Online Journal of
Education Technology. ISSN: 1303-6521 article 11, 7 (4).

[3] Hudojo, Herman. (2003). Pengembangan Kurikulum dan pembelajaran matematika (Curriculum development and mathematics learning). Malang: State University of Malang.

[4] National Council of Teacher of Mathematics. (2006). Curriculum Focal Points for Prekindergarten through Grade 8 Mathematics (A Quest for Coherence, Reston VA: Author ed.).

[5] National Research Council. (2006). Paying Attention to Spasial Reasoning (Support document for Paying Attention to Mathematics Education). (K.-1. N. Press., Ed.) Washington, DC.

[6] Ontario Ministry of Education. (2007). The Ontario Curriculum: Grade 11 and 12. (ON: Queen's Printer for Ontario ed.). Toronto:http://www.edu.gov.on.ca/eng/curric ulum/secondary/math 112 currb.pdf.

[7] Polya. (2004). How to Solve It: A New Aspect of Mathematical Method. Princeton, New

[8] Wuersch, M. \& Egenhofer, M. J. (2003). Perceptual Sketch Interpretation. Electronic Theses and Dissertations. Paper 576.

[9] Zuraidah. (2015). Reproduksi Visual Spasial Siswa SMK dalam Mengkonstruksi Kubus (Visual Spatial Reproduction of Vocational Students in Constructing Cubes). Dissertation. State University of Malang 